\title{
A leitura de textos em língua estrangeira "entre" a ideologia, a estrutura da linguagem e o desejo: uma abordagem discursiva
}

\section{Edmundo Narracci Gasparini Unicamp}

\begin{abstract}
Buscando explicitar o que seria uma abordagem "discursiva" do ato de ler textos em língua estrangeira, este artigo indica que a interpretação de textos numa língua outra se dá "entre" a estrutura linguística do texto (que se apresenta como opacidade aos olhos daquele que lê), as determinações sócio-históricas do discurso e a singularidade do leitor. Ao longo de nossa argumentação, tecemos também considerações críticas sobre o que chamamos de "abordagens interativas sobre leitura".
\end{abstract}

With the objective of discussing what a "discoursive" approach to foreign language reading would be like, this paper indicates that the interpretation of texts written in a foreign language takes place "among" the linguistic structure of the text (which is essentially opaque to the foreign language reader), the socio-historical determination of discourse and the uniqueness of the reader. We also critically discussed what could be called the "interactive approaches to foreign language reading".

\section{Introdução}

Este artigo tem como objetivo empreender uma reflexão crítica sobre o ato de ler textos em língua estrangeira a partir de uma perspectiva "discursiva" de linguagem. Para cumprir este objetivo, apresentaremos inicialmente um breve panorama histórico dos estudos sobre leitura em língua estrangeira no interior da Linguiística Aplicada, de forma a podermos aí situar o que seria uma abordagem "discursiva" do ato de ler textos em uma língua que não é materna. 


\section{Um panorama histórico dos estudos sobre leitura em língua estrangeira na lingüística aplicada.}

Evocamos aqui Carrell (1995) para afirmar que "as teorizações iniciais sobre leitura em segunda língua, especificamente sobre leitura em inglês como segunda língua, supunham uma visão bastante passiva e ascendente da leitura em segunda língua; isto é, a leitura era abordada fundamentalmente como um processo de decodificação [...]" (Carrell, op. cit.: 1-2-tradução minha) $)^{3}$.

Nesta perspectiva, seria possível dizer que a leitura se constitui como ato de reconhecimento das unidades lingüísticas do texto, o qual se configuraria então como se fosse depositário de um sentido imanente, cabendo ao leitor a mera extração das significações incutidas na letra através da decodificação linguiística. Segundo Carrell (op. cit.), o ato de ler se configura nesta perspectiva como processo passivo de mero reconhecimento do sentido intrínseco ao texto. Este tipo de processamento textual, com ênfase no "resgate do sentido" a partir das menores unidades lingüísticas, é conhecido como processamento ascendente ou "bottom-up", isto é, o processamento pelo qual o leitor parte dos elementos lingüísticos do texto e procede linearmente em direção ao sentido.

Com o advento da psicologia cognitiva e a conseqüente ênfase nos processos mentais envolvidos no ato de ler, as teorias sobre leitura começam a enfatizar o papel ativo do leitor no ato de interpretação textual. Goodman (1995) irá abordar a leitura como processo psicolingüístico, isto é, como processo em que está em jogo a relação entre o pensamento e a linguagem. Segundo este autor, a leitura

\section{é um processo psicolingüístico na medida em que começa com uma representação lingüística de superfície codificada por um autor e termina com o sentido construído pelo leitor. Há assim uma}

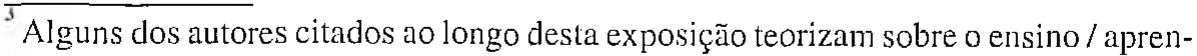
dizagem de leitura em segunda língua, e não em língua estrangeira. Acreditamos, entretanto, que a diferença entre ambas (o termo segunda língua se refere à situação de aprendizagem de uma língua outra em situação de imersão) não é relevante para o presente artigo.
} 
interação fundamental entre linguagem $e$ pensamento no ato de ler. $O$ autor codifica o pensamento em linguagem e o leitor decodifica a linguagem em pensamento. (Goodman, op. cit.: 12 - tradução minha).

Segundo Goodman (op. cit.), o "leitor eficiente" é aquele que minimiza sua dependência na informação gráfica; a construção de significado seria um processo cíclico e contínuo de retirar amostras do texto, fazer previsões, testá-las, confirmá-las ou refazê-las, e retirar mais amostras textuais. O leitor não precisa (e, idealmente, não deve) usar toda a informação gráfica do texto. Este tipo de processamento textual é conhecido como processamento descendente ou "top-down", através do qual o sentido textual é construído a partir do conhecimento de mundo do leitor, e não apenas dos grafismos do texto.

Na perspectiva cognitiva de leitura, a noção de "esquema" se reveste de importância especial. Os esquemas se referem a estruturas de conhecimento abstrato supostamente armazenadas na mente do leitor, estruturas estas que são como que "ativadas" durante o ato de leitura, de forma que seja possível interpretar a informação textual a partir das estruturas de conhecimento prévio do leitor. Nesta direção, podemos vislumbrar um primeiro significado possível para o termo "leitura interativa" (ao longo deste artigo, outros significados serão expostos). $\mathrm{O}$ ato de ler se configura na perspectiva cognitivista como "interação" entre o conhecimento de mundo do leitor e a informação contida no texto.

As chamadas "abordagens interativas de leitura" poderiam ser consideradas como um terceiro "momento teórico" no estudo da interpretação de textos em segunda língua/língua estrangeira. Após a ênfase na decodificação linguíística e, num segundo momento, o advento da psicologia cognitiva, a teorização interativa sobre leitura coloca em pauta a idéia de que as abordagens estritamente "bottom-up" ou "topdown" perdem de vista o fato de que, no ato de ler, ambos os níveis de processamento são utilizados. Nesta perspectiva, afirma-se a existência de uma certa "interação" entre diferentes níveis de processamento textual

\footnotetext{
"Veremos que, nestas "abordagens interativas de leitura", o termo "leitura interativa" se revestirá de uma significação um pouco diferente daquela exposta no parágrafo anterior.
} 
na compreensão do texto. Um modelo interativo de leitura é aquele que consegue integrar o processamento "bottom-up", ou seja, a decodificação linear dos menores itens lingüísticos do texto, ao processamento "topdown", que se refere à construção de sentido textual a partir do conhecimento prévio do leitor. Dentro da perspectiva interacionista, estes dois diferentes níveis de processamento textual exerceriam entre si uma influência recíproca, uma vez que deficiências no processamento em um dos níveis levaria a um incremento no uso do outro ${ }^{5}$. Nesta perspectiva, vê-se que o termo interação tem uma conotação original: trata-se, então, da influência mútua entre processamento ascendente e descendente no ato de interpretação textual. Eskey (1988) afirma que "os modelos interativos não pressupõem a primazia do processamento top-down [...] mas, antes, postulam uma constante interação entre processamento bottom-up e top-down" (Eskey, op. cit.: 93- 94 - grifo do autor; tradução minha).

Devemos abordar ainda um outro significado da expressão "leitura interativa", o qual se refere ao ato de ler como interação entre leitor e autor via texto. Kato (1999) afirma que

\section{com a incorporação das noções da pragmática, outra guinada é observada. O foco passa a ser não mais sobre o que o texto diz em função da interação do leitor com os dados lingüísticos, mas sobre o que o autor quis dizer, isto é, suas intenções. Nessa visão, o ato de ler passa a ser visto como um ato comunicativo. (Kato, op.cit.: 114-115)}

A "guinada da pragmática" mencionada por Kato (op.cit.) coloca em cena a idéia de que o texto seria lugar de uma "intenção do autor", a qual deveria ser captada pelo leitor no ato de interpretação textual. Nesta perspectiva, uma leitura "adequada" seria aquela em que o leitor, fazendo uso de seu conhecimento prévio e das pistas lingüísticas deixadas pelo autor do texto, consegue captar as "intenções" deste último. É relevante

\footnotetext{
A idéia de que uma deficiência no processamento em um dos níveis leva a um incremento no uso de processamentos de outro nível foi elaborada por Stanovich com a noção de "processamento compensatório". A este respeito, cf. Samuels e Kamil (1995).
} 
notar que, na citação anterior, Kato (op. cit.) faz menção ao ato de ler como "ato comunicativo". Na perspectiva da "captação" da intenção do autor, a leitura se configura como ato de transmissão de informação, como se o autor comunicasse (via texto) suas intenções ao leitor.

Abordar a leitura em língua estrangeira como processo discursivo representa uma ruptura em relação à forma pela qual o ato de ler é tradicionalmente concebido na produção teórica da Lingüística Aplicada. A noção de discurso coloca em cena elementos incompatíveis com a concepção de leitura como processo exclusivamente "bottom-up" ou "top-down", ou ainda como interação entre estes dois diferentes níveis de processamento. Fazer referência ao jogo discursivo também representa uma ruptura em relação ao ato de ler abordado como interação entre o leitor e o autor via texto. Tentaremos agora esboçar de que ordem seria esta incompatibilidade entre as teorias discursivas e as teorias "interativas" referentes ao ato de ler em língua estrangeira ${ }^{6}$. Para tanto, teceremos algumas considerações críticas a respeito do que poderíamos chamar de "discurso interacionista sobre leitura".

Inicialmente, deve-se dizer que as teorias interativas de leitura colocam em cena uma concepção essencialista de texto. Na teorização sobre leitura como processo interativo, a escritura aparece como mero suporte de significações existentes a priori no mundo. Apesar de algumas dessas teorias enfatizarem a relevância do conhecimento de mundo do leitor no ato de interpretação textual, as abordagens interativas estão, na realidade, operando com a idéia de que o texto contém um sentido necessário, intrínseco. A esse respeito, faz-se necessário tecer algumas considerações sobre a abordagem cognitiva do ato de ler textos em língua estrangeira. O cognitivismo coloca em pauta o fato de que existiriam, a priori, os esquemas considerados "adequados" para a interpretação de um dado texto. Carrell e Eisterhold (1995) afirmam que "a falha do leitor em ativar um esquema apropriado [...] durante o ato de leitura resulta em vários graus de não-compreensão" (Carrel e Esterhold, op. cit.: 80 grifo meu; tradução minha). Dessa forma, é como se um texto pressupusesse, de forma necessária, um conhecimento de mundo

\footnotetext{
$\mathrm{Na}$ argumentação que se segue, faremos uso do termo "teorias interativas de leitura" para nos referirmos à produção teórica da Linguística Aplicada apresentada até agora neste artigo. Com exceção das teorias de leitura estritamente "bottom-up", todas as outras teorias aqui expostas poderiam ser chamadas de "interativas".
} 
"adequado" para a sua compreensão (independente da singularidade do ato de leitura), conhecimento este que deve ser "ativado" na mente do leitor de forma que uma leitura "bem sucedida" seja realizada. Ora, se um texto pressupõe determinados esquemas "adequados" para sua compreensão "adequada", então poderíamos dizer que ele supostamente é lugar de uma significação intrínseca e necessária, independente da especificidade do ato de Ieitura.

Em relação a este "essencialismo do texto" constitutivo das abordagens interativas de leitura, devemos também chamar a atenção para o fato de que a noção de intenção do autor, colocada em cena a partị da "incorporação das noções da pragmática" (Kato, 1999: 114), também configura a escritura como mero suporte de signifjcações. Neste caso, o texto seria como que o lugar onde o autor inscreve sua intenção consciente, intenção esta que deve ser resgatada no ato de interpretação textual. Destarte, seja como materialidade que requer a ativação de esquemas "apropriados", seja como espaço de inscrição da intenção do autor, o texto é abordado nas teorias interativas sobre leitura como suporte de significações, como lugar onde se inscreve um sentido necessário, sentido este a ser resgatado no ato de interpretação textual.

É relevante notar que existe, na própria teorização interativa sobre leitura, uma crítica à concepção "essencialista" de texto. Critica-se a noção de leitura como resgate de significações inerentes à escritura, independentemente do leitor e do contexto de leitura. Carrell e Eisterhold (1995) afirmam que
O papel do conhecimento de mundo na compreensão foi formalizado como teoria dos esquemas [...], a qual tem como um de seus princípios fundamentais o fato de que um texto, seja ele oral ou escrito, não contém um significado em si. (Carrell e Eisterhold, op. cit.: 76 - grifo dos autores; tradução minha).

Ora, isto indica que o discurso interacionista sobre o ato de ler é marcado por um paradoxo. Critica-se uma concepção "essencialista" de texto, mas sua própria teorização coloca a escritura como portadora de uma essência estável (o sentido intrínseco que demanda esquemas "adequados" ou a intenção do autor). Acreditamos que tal paradoxo pode 
ser exemplificado se fizermos novamente uso de um trecho do texto de Carrell e Eisterhold (1995). Após indicarem que "um texto [...] não contem um significado em si" (op. cit.: 76 - tradução minha), os autores, em relação à falha do leitor em ativar um "esquema apropriado [...] durante a leitura" (op. cit.: 80 - tradução minha), afirmam tratar-se de "uma incongruência entre o que o autor antecipa que o leitor pode fazer para extrair sentido do texto e o que o leitor é de fato capaz de fazer" (op. cit: 80 - grifo meu; tradução minha). As abordagens interativas de leitura parecem se constituir a partir de um "contra-senso teórico", pois sua teorização se constitui a partir de uma ilusão (o "essencialismo do texto"), ilusão esta que é questionada em sua própria teorização. As teorias interativas colocam em cena uma crítica a algo que as constitui, o que aponta para a inconsistência de sua argumentação.

O "essencialismo do texto" colocado em cena pelas abordagens interativas de leitura se encontra acompanhado de uma determinada forma de compreender o sujeito que lê um texto em língua estrangeira. A este respeito, Kato (1999) afirma que o Jeitor "maduro"
usa, de forma adequada e no momento apropriado, os dois processamentos complemen- tarmente [o "top-down" e o "bottom-up"]. É o leitor para quem a escolha desses processos é já una estratégia metacognitiva, isto é, é o leitor que tem um controle consciente e ativo de seu comportamento. (Kato, op. cit.: 51)

A partir desta citação, poderíamos dizer que as abordagens interativas de leitura estariam operando com uma determinada forma de compreender o sujeito, forma esta que parece colocar em pauta sua suposta "consciência". O leitor seria capaz de fazer um uso "adequado" tanto da decodificação do texto quanto do seu conhecimento de mundo, pois supostamente seria capaz de fazer uma escolha "consciente" entre estes dois tipos de processamento textual. Na perspectiva interacionista de leitura em língua estrangeira, o sujeito é aquele que tem (ou que, idealmente, deve ter) um "controle consciente e ativo de seu comportamento" (Kato, idem) no ato de interpretação textual.

O engodo da consciência do sujeito colocado em jogo pelas teorias interativas pode também ser abordado através da noção de "intenção do 
autor". Se o autor é concebido como alguém que inscreve no texto sua "intenção", então poderíamos dizer que ele se configura como alguém que tem uma clareza de idéias sobre o que quer expressar quando escreve um texto. A noção de "intenção do autor" aponta para uma determinada forma de compreensão do sujeito, qual seja, aquela que coloca em jogo sua consciência, ou seja, seu controle consciente em relação à expressão de sentidos. Destarte, seja em relação a um suposto "controle consciente" sobre o ato de ler, seja em relação à clareza de idéias do autor sobre sua "intenção", as abordagens interativas colocam em pauta a ilusão do sujeito centrado, que teria pleno controle sobre o seu dizer e fazer.

Em nossa tentativa de tecer considerações críticas sobre as abordagens interativas de leitura, faz-se também necessário mencionar que estas abordagens parecem colocar em pauta uma constante normatização do ato de interpretação textual. Partindo do pressuposto de que "o processamento textual mais eficiente é interativo - uma combinação de processamento top-down e bottom-up" (Carrell, 1995a: 101 - grifo meu; tradução minha), o discurso interacionista põe em cena a idéia do "bom leitor" ou do "leitor maduro". Este seria aquele que "usa, de forma adequada e no momento apropriado, os dois processamentos complementarmente" (Kato, 1999.: 51). Vê-se que a padronização relativa ao que supostamente seria uma "leitura eficiente" leva a uma normatização dos comportamentos do leitor. O leitor "maduro" seria aquele que faz um uso "equilibrado" de estratégias ascendentes e descendentes no ato de interpretação de um texto. Devese indicar que esta padronização não deixa de ser uma forma de controle e homogeneização do ato de ler através da referência a uma norma.

A respeito desse controle do ato de interpretação textual através de uma padronização dos comportamentos do leitor, poderíamos evocar um determinado ponto da teorização de Michel Foucault (1987a) sobre a questão do poder. Realizando uma comparação entre a mecânica do poder nas monarquias e na sociedade capitalista, o filósofo afirma que os mecanismos de poder na monarquia, centrados na figura do rei, eram muito lacunares, sendo que era impossível praticar uma análise exaustiva e individualizante do corpo social (a individualização era máxima do lado de quem exercia o poder). O sistema era por demais global. No século XVIII, fez-se necessário fazer circular efeitos de poder por canais mais disseminados, chegando ao indivíduo, seu corpo, seus gestos e desempenhos cotidianos. No que se refere a uma abordagem histórica 
do tratamento dispensado aos criminosos, Foucault afirma que a passagem do "punir" para o "vigiar" se relaciona à descoberta de um outro poder, um poder sutil, microscópico e capilar que se exerce o mais anonimamente possível e que deve ser sofrido individualmente. A questão não seria punir, mas fazer com que as pessoas nem pudessem agir mal, pois se sentiriam vigiadas por um olhar imediato, coletivo e anônimo. Este poder pelo olhar, menos oneroso política e economicamente e que age individualmente, é o que Foucault chama de poder disciplinar. Sua ação individualizante se dá através de uma vigilância constante e de medidas comparativas que têm uma norma como referência. Ora, a normatização do ato de ler textos em língua estrangeira colocada em cena pelas abordagens interativas de leitura (através da noção do "bom leitor" ou do "leitor maduro") pode ser pensada em relação a este exercício "sutil" e "microscópico" do poder na sociedade capitalista, pois o que está em jogo nestas abordagens é justamente um "adestramento" do ato de ler textos em língua estrangeira em relação a uma norma considerada "boa", "madura" ou "correta"

\section{Leitura em língua estrangeira: Uma abordagem discursiva}

Talvez estejamos agora em condições de abordar a seguinte questão: em que sentido uma perspectiva "discursiva" do ato de ler textos em língua estrangeira marca uma ruptura em relação às abordagens interativas de leitura? En relação a essa questão, Coracini (1995) afirma que $o$ ato de leitura em língua estrangeira se constitui como produção de sentidos historicamente determinada, ou seja, como "um processo discursivo no qual se inserem os sujeitos produtores de sentido" (Coracini, op. cit.:15). Portanto, diríamos que a interpretação de textos em língua estrangeira se configura' no jogo discursivo, isto é, na rede histórica de constituição do sentido. Não é o texto que determina a interpretação, mas sim o sujeito em sua constituição histórica. É apenas num nível imaginário que o texto tem uma significação intrínseca; esta ilusão necessária é um efeito da ideologia, que opera apagando as condições (sócio-históricas) de produção da interpretação e produzindo o imaginário do sentido imanente. Perceber o texto como mero suporte de significações significa "refletir", na teoria, o efeito ideológico que produz a ilusão do sentido inerente à letra. 
$\mathrm{O}$ ato de ler textos em língua estrangeira abordado como processo discursivo também coloca em xeque a idéia de que o leitor possua uma "consciência" em relação à interpretação de textos. O sujeito que lê um texto em língua estrangeira não possui um controle consciente sobre os sentidos que produz ou sobre quais seriam as "estratégias" "adequadas" para a leitura de um texto. Abordar o ato de ler como processo discursivo implica efetuar um descentramento da consciência do leitor em direção à trama histórica constitutiva dos discursos. A este respeito, Coracini (op. cit.) enfatiza a condição de "sujeito" do leitor, "não na acepção idealista de indivíduo, uno, coerente [...], mas enquanto participante de uma determinada formação discursiva, sujeito clivado, heterogêneo" (Coracini, op.cit.:17).

Portanto, vemos que compreender o ato de ler textos em língua estrangeira como processo discursivamente determinado se apresenta como ruptura em relação à teorização interativa sobre a leitura. $\mathrm{O}$ jogo discursivo põe em cena o fato de que o sujeito não possui nenhuma "clareza de idéias" sobre os sentidos que produz, uma vez que é na historicidade do discurso que os sentidos se constituem. Por outro lado, abordar a leitura como processo discursivo também questiona a idéia de que o texto é possuidor de um significado intrínseco e necessário. Só o sujeito pode conferir sentido à materialidade lingüística do texto.

Cabe, entretanto, realizar o seguinte questionamento. Se, de acordo com nossas considerações, o texto não contém um significado, ou seja, se a interpretação necessariamente coloca em cena o sujeito que interpreta, qual é então o lugar do texto no ato de interpretação? Ou ainda: se a leitura tem uma constituição histórica na trama do discurso, como se configura a escritura numa abordagem discursiva do ato de ler? A este respeito, poderíamos citar Eco (1997), que afirma que

dizer que a interpretação [...] é potencialmente ilimitada não significa que a interpretação não tenha objeto e que corra por conta própria. Dizer que um texto potencialmente não tem fim não significa que todo ato de interpretação possa ter um final feliz. (Eco, op. cit.: 28)

O autor parece querer marcar o fato de que, se, por um lado há interpretação, por outro não devemos esquecer que existe também um 
"objeto interpretado". Entretanto, cabe ainda perguntar: se não é um "sentido" que o texto possui, o que é que a escritura põe em cena quando se trata da interpretação de um texto? Mais uma vez, é Eco (op. cit.) que vem em nosso auxílio. Segundo o autor,

as palavras trazidas pelo autor são um conjunto um tanto embaraçoso de evidências materiais que o leitor não pode deixar passar em silêncio, nem em barulho. (Eco, op. cit.: 28)

É relevante notar que Eco (op. cit.) faz referência a uma "evidência material" das palavras, evidência esta que "o leitor não pode deixar passar" (Eco, op. cit.: 28). Portanto, fica aqui indicado que se, por um lado, um texto não contém um "sentido", por outro ele é lugar de uma "materialidade lingǘstica", materialidade esta que exercerá efeitos na forma pela qual a interpretação do texto se constitui. Se existe um "objeto a ser interpretado", este "objeto" se refere à "evidência material" das palavras mencionada por Eco (op. cit.), ou seja, à materialidade significante do texto. A interpretação é discursivamente determinada, mas ela se refere a uma materialidade lingüística que, se por um lado não possui um significado, por outro não deixa de exercer efeitos na produção de sentidos do leitor.

Devemos, ainda, abordar um ponto importante para nossa caracterização "discursiva" do ato de ler textos em língua estrangeira. Se o ato de interpretação textual tem como objeto a escritura em sua materialidade significante, o que se passa quando esta materialidade "não é materna", ou seja, quando o objeto interpretado está escrito numa língua estrangeira? Ou ainda: a interpretação de textos em língua estrangeira teria alguma especificidade em relação ao ato de ler textos em língua materna? Em relação a esta questão, poderíamos evocar aqui Coracini (1998), segundo a qual a língua estrangeira pode ser pensada como "língua 'estranha', língua do outro, do desconhecido" (Coracini, op. cit.: 158). Fazendo menção a um certo "estranhamento do dizer na outra língua" (Coracini, op. cit.: 164), a autora parece afirmar que uma língua estrangeira põe em cena uma materialidade que se apresenta como "desconhecida" e "estranha" aos olhos daquele envolvido em sua aprendizagem. Em relação ao ato de ler textos em língua estrangeira, poderíamos dizer que este "estranhamento" deve ser pensado em relação 
ao fato de que é como não-transparência que a materialidade lingüística "não-materna" se apresenta aos olhos do leitor. A interpretação de textos em língua estrangeira se coloca para o leitor como ato de lidar com uma materialidade outra, materialidade esta que se apresenta como "opacidade" para aquele que lê. Um dos atributos da linguagem é sua não-transparência, isto é, o fato de que o sentido não tem uma relação transparente e óbvia com a linguagem. Entretanto, a língua estrangeira (como língua do "desconhecido") põe em cena um outro tipo de opacidade, desta vez, relacionada a uma língua "'estranha', língua do outro, do desconhecido" (Coracini, op. cit.: 158). Ao lado da opacidade da linguagem, existe também a opacidade específica de uma língua que não é materna.

Antes de encerrarmos, devemos ainda abordar um ponto importante em nossa caracterização da leitura em língua estrangeira como processo discursivo. Se, por um lado, qualquer ato de leitura põe em cena as determinações históricas do discurso, por outro, a historicidade não exerce seus efeitos sem que acontecimentos imprevisíveis e aleatórios irrompam no próprio ato de interpretação textual. Destarte, não poderíamos deixar de mencionar que o ato de ler textos em língua estrangeira é lugar de irrupção do novo e do imprevisível, lugar onde o sujeito desponta em sua singularidade, para além da configuração histórica da significação. Na determinação histórica dos atos de leitura em língua estrangeira, acontecimentos inesperados presentificados pelo sujeito não deixam de irromper. Colocando em jogo o novo e o imprevisível, a produção do sujeito em atos de interpretação textual pode se apresentar como contradição em relação à configuração do sentido na trama histórica, ou seja, em relação à ordem do discurso instituído.

Em relação à questão de que o ato de ler textos em língua estrangeira se dá "entre" a reprodução histórica de sentidos e a produção de significações novas, a teoria psicanalítica de Sigmund Freud e sua leitura por Jacques Lacan se tornariam aqui relevantes, pois o sujeito colocado em cena pela Psicanálise é justamente aquele cujo dizer e fazer "rompe" com a linearidade do imaginário discursivo. A partir da teoria psicanalítica, seria possível dizer que é ao colocar em jogo sentidos novos e inesperados que o sujeito se constitui como sujeito inconsciente, sujeito de desejo, sujeito que não se reduz às determinações ideológicas do discurso. 


\section{Considerações finais}

Através deste artigo, buscamos indicar que é "entre" a estrutura da linguagem, a historicidade do discurso e a singularidade do leitor que o ato de ler textos em língua estrangeira se configura. É "entre" a "evidência material" (cf. Eco, 1997) de um texto, as determinações ideológicas do discurso e o leitor em sua singularidade desejante que toda interpretação de textos em língua estrangeira se configura? ${ }^{7}$. Devemos novamente lembrar que, ao lado da opacidade da linguagem, isto é, ao fato de que a linguagem não tem uma relação transparente e óbvia com o sentido, existe também uma opacidade específica a uma língua que não é materna, língua “"estranha', língua do outro, do desconhecido" (Coracini, 1998a: 158). Destarte, diríamos que é como uma opacidade que causa "estranhamento" que um texto em língua estrangeira se apresenta aos olhos daquele que se propõe a interpretá-lo.

Ler textos numa língua outra implica aceitar o desafio simbólico de uma língua "estranha". Frente ao desafio presentificado pelo "estranho" e pelo desconhecido, ou seja, face à opacidade de textos escritos numa língua outra, pode-se facilmente retroceder para a língua materna ou para a ordem ideologicamente constituída das significações estabelecidas e ignorar que existe uma materialidade significante a ser interpretada. A opacidade da língua estrangeira pode fazer com que a interpretação se configure como ato de reprodução de sentidos que desconsidera a "evidência material" (cf. Eco 1997: 28) do texto interpretado. Frente a esse estado de coisas, acreditamos que aqueles envolvidos com o ensino de leitura em língua estrangeira devem ter um "compromisso ético", qual seja, evitar que a aula de leitura se constitua como mero ato de reprodução ideológica de sentidos. Para tanto, não desconsiderar a "evidência material" (cf. Eco op. cit.: 28) do texto interpretado se constitui como uma importante contribuição para promover uma pedagogia que, se por um lado não escapa às injunções imaginárias da ideologia, por outro deve ir além da reprodução histórica de sentidos.

A questão do desejo e da singularidade do sujeito pode também ser pensada em relação a esse "compromisso ético" daqueles envolvidos

\footnotetext{
Poderíamos dizer o mesmo sobre o ato de ler textos em língua materna.
} 
com a pedagogia de leitura em língua estrangeira. $\mathrm{O}$ ensino de leitura numa outra língua deve se configurar como espaço onde o leitor assume sua condição desejante, ou seja, se assume enquanto sujeito possuidor de uma singularidade, para além das determinações ideológicas de sentido. As inevitáveis injunções imaginárias da ideologia não devem fazer com que as aulas de leitura em uma outra língua se configurem como espaço de "exclusão" do sujeito. E, devemos lembrar, uma vez "excluído" da cena pedagógica, o sujeito "aparece em outros lugares": na "indisciplina", no desinteresse em relação às aulas, na falta de motivação, etc.

Ao longo deste artigo, tecemos algumas considerações críticas sobre o que chamamos de "discurso interacionista sobre leitura". Gostaríamos de indicar que o fato de termos criticado alguns pontos deste discurso não quer dizer que acreditemos que as pesquisas "interativas" sobre leitura sejam desprovidas de valor. Tais pesquisas certamente promoveram "insights" valiosos para a pedagogia de leitura em língua estrangeira. Apenas acreditamos que, apesar da contribuição das "teorias interativas" para o ensino de leitura, elas apresentam inconsistências que devem ser abordadas.

\section{Referências bibliográficas}

ALTHUSSER, L. Aparelhos ideológicos de estado. Rio de Janeiro: Graal, 1998.

CARRELL, P. Introduction: Interactive approaches to second language reading. In: CARRELL, P., DEVINE, J. e ESKEY, D., (Orgs.) Interactive approaches to second language reading. Cambridge: Cambridge University Press, 1995. p. 1-7.

- Some causes of text-boundedness and schema interference in ESL reading. In: CARRELL, P., DEVINE, J. e ESKEY, D., (Orgs.) Interactive approaches to second language reading. Cambridge: Cambridge University Press, 1995. p. 101-113.

CARRELL, P., DEVINE, J. e ESKEY, D., Interactive approaches to second language reading. Cambridge: Cambridge University Press, 1995.

CARRELL, P. e EISTERHOLD, J. Schema theory and ESL reading Pedagogy. In: CARRELL, P., DEVINE, J. e ESKEY, D., (Orgs.) 
Interactive approaches to second language reading. Cambridge: Cambridge University Press, 1995. p. 73-92.

CORACINI, M. J. (Org.) O Jogo discursivo na aula de leitura. Campinas: Pontes, 1995.

A escamoteação da heterogeneidade nos discursos da Lingüística Aplicada e da Sala de Aula. LETRAS, Santa Maria, 14, p. 39-64, 1997.

- Língua estrangeira e língua materna: uma questão de sujeito e identidade. Letras \& Letras, Uberlândia, v.14, n.1, p.153-169, 1998.

ECO, U. Interpretação e superinterpretação. Martins Fontes: São Paulo, 1997.

ESKEY, D. Holding in the bottom: an interactive approach to the language problems of second language readers. In: CARRELL, P., DEVINE, J. e ESKEY, D., (Orgs.) Interactive approaches to second language reading. Cambridge: Cambridge University Press, 1995. p. 93-100.

FOUCAULT, M. A Arqueologia do saber. Rio de Janeiro: Forense, 1987. . Vigiar e punir. Petrópolis: Vozes, 1987a. . A Ordem do discurso. São Paulo: Loyola, 1996.

FREUD, S. A Interpretação dos sonhos. In: Edição standard brasileira das obras completas de S. Freud. Rio de Janeiro: Imago, 1969. v. 5 e 6. GOODMAN, K. The reading process. In: CARRELL, P., DEVINE, J. e ESKEY, D., (Orgs.) Interactive approaches to second language reading. Cambridge: Cambridge University Press, 1995. p. 11-21.

KATO, M. O aprendizado da leitura. São Paulo: Martins Fontes, 1999. KLEIMAN, A. B. Modelos teóricos: fundamentos para o exame da relação teoria e prática na àrea de leitura. Trabalhos em Lingüística Aplicada, Campinas, 3, p. 5-21, 1984.

LACAN, J. Função e campo da fala e da linguagem em psicanálise. In: Escritos. Rio de Janeiro: Zahar, 1998. p. 238-324.

. O seminário sobre "A Carta Roubada". In: Escritos. Rio de Janeiro: Zahar, 1998a. p. 13-66.

LEITE, N. Psicanálise e a Análise do discurso. Rio de Janeiro: Campo Matêmico, 1994.

ORLANDI, E. P. (Org.) A leitura e os leitores. Campinas: Pontes, 1998. 

. Interpretação. Petrópolis: Vozes, 1998a. . Discurso e leitura. São Paulo: Editora da Unicamp, 1999a. PÊCHEUX, M. Análise automática do discurso. In: GADET, F. e T. HAK (orgs.) Por uma análise automática do discurso - uma introdução à obra de Michel Pêcheux. Campinas: Unicamp, 1997. p. 61-161. Pontes, 1997.

Discurso: estrutura ou acontecimento? Campinas:

e FUCHS, C. A propósito da análise automática do discurso: atualização e perspectivas. In: GADET, F. e T. HAK (Orgs.) Por uma análise automática do discurso - uma introdução à obra de Michel Pêcheux. Campinas: Unicamp, 1997. p. 163-253.

SAMUELS, S. e KAMIL M. Models of the reading process. In: CARRELL, P., DEVINE, J. e ESKEY, D., (Orgs.), Interactive approaches to second language reading. Cambridge: Cambridge University Press, 1995. p. 22-36.

SAUSSURE, F. Curso de lingüística geral. São Paulo: Cultrix, 1974. 